\title{
UNCSTD success still hangs in the balance
}

\section{David Dickson reports from New York on final preparations for the UN Conference on Science and Technology for Development}

With less than six weeks to go before official proceedings open in Vienna, a cloud of uncertainty still hangs over the chances of any major achievements coming out of the United Nations conference on Science and Technology for Development.

Delegates attending the fifth and final meeting of the conference's preparatory meeting in New York last week managed to reach agreement on a number of proposals that will be put to the conference as part of a 'plan of action' which the conference will be urged to adopt. However there are still major differences in three of the key areas to be discussed - the transfer of technology, and the institutional and financial procedures necessary to implement the decisions of the conference - and the stage has now been set for some hard bargaining over these in Vienna.

In general, the developing countries are seeking ways to improve their bargaining position over acquiring technology from the industrialised countries, to gain additional funds from these countries to build up their scientific and technological efforts, and to make the UN system more responsive to their needs in these areas by increasing their control over the relevant decision-making processes. In contrast, the industrialised countries, quoting domestic, economic, and political problems of their own, are keen to discuss specific areas of scientific and technological assistance, but have so far been digging their heels in over agreeing to any major procedural changes or financial commitments.

Most of the two-week session was spent by delegates in closed drafting meetings discussing, paragraph by paragraph, proposals for a new plan of action. The plan has been compiled by the Group of 77 (to which over 120 developing countries now belong) as an alternative to proposals put forward by the conference secretariat.

Agreement was reached on a number of proposals, mostly on relatively uncontroversial areas dealing with the internal arrangements that developing countries should make in order to increase their scientific and technological capabilities.

There were difficulties, however, whenever a paragraph arose that involved - or seemed to involve - the developed countries making any type of commitment to change existing arrangements. The developing countries have essentially used the proposed plan of action as the occasion to make a detailed statement of principle on what, they feel, should be done by developed countries and the United Nations bodies in the area of science and technology for development. In contrast, the developed countries - with a few notable exceptions, particularly the Nordic countries - claim that such statements imply definite commitments of the type which many of the negotiators said they were unable to make.

The result is that when delegations arrive in Vienna, they will be faced with a series of documents liberally peppered with square brackets containing alternative formulations of key proposals. For example, where the Group of 77 suggests that the plan of action say "developing countries should be able to play a more effective role at the decision-making level in international organisations", the EEC suggests the same paragraph should read "all countries should...". Similarly, where the developing countries are demanding "full access" to western technology, the developed countries want this changed to "freest and fullest possible" access, a qualifier that dilutes the initial intent.

Three areas of disagreement remain. The first is the general area of technology transfer. Here the developing countries, in line with the stance taken in other UN forums, are demanding substantial concessions in their terms of access to the technology of the developed world. Industrialised countries, in contrast, are refusing to make any significant concessions, arguing partly that this is the responsibility of the private sector over which they have no control, and also that the issues are already being dealt with sufficiently elsewhere. The second area of disagreement is over the financial support needed to carry out the conference's recommendations. The Group of 77 argue that this can only be done with a considerable increase in the transfer of funds from the developed countries. They have suggested setting up a new financing system, largely financed by the industrial world, with a provisional target of $\$ 2$ billion by 1985 and $\$ 4$ billion by 1990 .

The industrialised countries, however, themselves to any increase in such contributions. They are particularly critical of the suggestions that they be required to make "automatic" contributions to such a fund on the basis of, for example, their trade surplus in manufactured goods with the developing world.

Financial issues are also linked to the third area of disagreement, namely what changes should be carried out in the UN system to implement the conference proposals. The developed countries would like to see the strengthening of existing bodies, in particular the UN's economic and social council, to do this, although accepting that the status of science and technology should be raised within general have made clear their reluctance to commit development strategies.

In contrast, the developing countries, distrusting what they consider to be the undue dominance of the industrialised countries in ECOSOC, want a new intergovernmental body to be set up. This might report directly to the General Assembly, with an executive general secretariat possibly established under the recently created UN post of DirectorGeneral for Development and International Co-operation.

A critical factor in this debate is likely to be the United Nations Development Programme. Although it has so far done relatively little explicitly concerned with science, UNDP has both wide experience of development issues and a high credibility among third world countries, and it may well be given operational responsibility, with an increase in funds, for decisions made by the intergovernmental committee in line with UNCSTD's final recommendations.

One phenomenon noted by a number of delegates at the meeting was an apparent softening of the US negotiating tactics. According to those who attended the closed drafting sessions, whereas the US had previously been pushing a relatively hard line in negotiations, disputing even relatively small points, they have subsequently slightly relaxed their stance, leaving the hard line more to the EEC countries ("and the British were the toughest of the lot" said one South American delegate).

Some have suggested that this shift in tactics may partly reflect a change of strategy by the transnational companies, eager to maintain their links with third world markets, but coming under increasing pressure from third world governments (particularly after the failures of UNCTAD V in Manila), and being forced to be more conciliatory.

Given the uncertainties that still remain, delegates leaving New York expressed views ranging from "concerned pessimism" to "cautious optimism" about chances of a significant agreement on these issues being made in Vienna. Much will depend on what happens in the negotiations between now and the end of August. The Group of 77 is meeting in Bucharest to discuss its negotiating strategy at the conference and others are meeting elsewhere.

On one point, however, the secretariat had its way. On the first day of the conference, the initial proceedings will include a performance of Beethoven's Fidelio overture. Some had complained that this would be time-wasting; others that, as western music, it might not be appreciated. The secretariat has defended its choice by pointing to the music's radical theme - and after all, you can't go to Vienna without listening to music. 